\title{
Male Involvement in Childcare in Hunter-gatherer Societies: An Empirical Study in Semaq Beri, Malaysia
}

\author{
Shingo Odani ${ }^{1}$ \\ ${ }^{1}$ Faculty of Letters, Chiba University, Chiba, Japan \\ Correspondence: Shingo Odani, Faculty of Letters, Chiba University, Chiba, 263-8522, Japan. Tel: \\ 81-43-290-2298. E-mail: odani@L.chiba-u.ac.jp
}

Received: August 2, $2012 \quad$ Accepted: August 21, $2012 \quad$ Online Published: November 30, 2012
doi:10.5539/ass.v8n15p53
URL: http://dx.doi.org/10.5539/ass.v8n15p53

\begin{abstract}
This study investigates gender roles in childcare among Semaq Beri people who have been classified into hunter-gatherer living in the state of Pahang in Peninsular Malaysia. The perpose of this study is to verify recent anthropological studies suggesting that males in hunter-gatherer societies are more involved in childcare than males in other societies. The results show a significant difference in proximity maintenance for the child: mothers spent more time with their children than fathers did. On the other hand, there were no significant differences in holding and carrying behavior between the father and mother. The main finding of this study is that the amount of time fathers spent holding and carrying children was considerably high. Studies conducted from an evolutionary point of view found that this result is common in hunter-gatherer societies. However, earlier studies suggested that male involvement in childcare could also be observed during other activities. The results of this study did not show such generality. Aditionally, the results of this study show that people other than parents tended to not participle in childcare.
\end{abstract}

Keywords: hunter-gatherer, Semaq Beri, Orang Asli, Malaysia, childcare, gender role, anthropology

\section{Childcare in Hunter-gatherer Societies}

Owing to an increase in discussions on gender relationships in recent years, scholars are placing greater focus on studying male involvement in childcare in hunter-gatherer societies. In Japanese and Western societies, for example, the requirement for male involvement in childcare has increased due to the growing structural demands of aging societies and perceptions regarding gender egalitarianism. In spite of these structural demands, in many societies, the "myths of motherhood" that insist that childcare is a biologically determined role of women still prevail (Thurer 1995). However, empirical studies that quantify childcare activities in various societies are few.

Although quantitative studies using statistical data collected from modernized societies are plentiful (e.g., National Women's Education Center of Japan 2007), almost all of the data were collected through sample surveys. A sample survey is a powerful method of data collection. However, it has limited value because it is difficult to directly compare subjects' social or biological backgrounds and behavior. In addition, large-scale surveys conducted among diverse populations in the Third World involve technical and political difficulties. This study explores the issue in an anthropological context and adopts anthropological methods to collect empirical data. This enables us to compare the background and behavior directly.

Hewlett (1991) stated that, since the earliest times, Homo sapiens have sustained themselves as hunter-gatherers. He suggests that a careful study of male involvement in childcare in hunter-gatherer societies may provide key information about "essential" gender roles in childcare. Although research on this topic is limited, recent empirical studies show that males in hunter-gatherer societies are more involved in childcare than males in other societies (Blurton Jones 1993). Researchers who based their work on evolutional theory discussed male involvement by using the parental investment theory (Katz and Konner 1981), focusing on whether paternal investment in children improves reproductive success. Recently, however, anthropologists engaged in fieldwork in hunter-gatherer societies have begun to question this evolutional viewpoint. Instead, they suggest that contemporary environmental factors affect gender roles in childcare (Konner 2005).

This study investigates gender roles in childcare among Semaq Beri people who live in the state of Pahang in Peninsular Malaysia. Throughout their history, Semaq Beri have depended on hunting and gathering for their 
sustenance (Kuchikura 1988). For discussing that gender roles in childcare are "genetic" or "environmental", Semaq Beri are one of most adequate subjects. Almost all previous studies on gender roles in childcare among hunter-gatherers were conducted in Africa. For theories to be generalizable, it is imperative that studies quantifing childcare activities be conducted in other regions as well. At present, a few ethnographic data are available that focuses on gender roles among Orang Asli societies (the indigenous people of Peninsular Malaysia) (Note 1). Semaq Beri have been classified as one of Orang Asli.

Bateq are an Orang Asli hunter-gatherer group that lives in close proximity to Semaq Beri. The group has been described as a gender egalitarian society, based on aspects of its micropolitical, subsistence, and childcare activities (Endicott and Endicott 2007, Endicott 1992). In their research, Endicott and Endicott discussed recent changes in gender roles in relation to modernization and "Malayanization" (Note 2). Kuchikura stated that Semaq Beri who lived in Terrenganu displayed biased gender roles in subsistence activities. Men primarily engaged in cash earning activities, while women engaged in housekeeping activities. Kuchikura noted, however, that gender roles in childcare activities among the Semaq Beri were not biased. For example, he found no difference between men and women in the amount of time spent in holding or watching behavior. Based on Kuchikura's findings, we conclude that aspects of biased and non-biased activities coexist ambiguously.

Among Orang Asli hunter-gatherer societies, gender roles, including those involving childcare activities, have been impacted by both long-term human history and short-term social change. In order to analyze the impact of these issues, quantitative data on their daily activities are needed. The long-term issue of the impact of human history relates to society's current identity problems, while the short-term issue of the impact of social change relates to existing social problems. An investigation of childcare activities can provide useful insights on issues regarding the wellness and education of those in Orang Asli societies in Malaysia and across the world.

\section{Sungai Kuching Community}

Fieldwork was conducted from September through October 2002 in Sungai Kuching village (Figure 1) located in Negeri Pahan (the state of Pahang). This village is one of several permanent settlements built by JHEOA (Jabatan Hal Ehwal Orang Asli; The department of Aboriginal Affairs Malaysia) (Note 3), along Tembeling River, a branch of the Pahan River. In the 1960s, the state began to build permanent settlements in the area. Construction was politically motivated in response to activities of the Malayan Communist Party, which operated in the forests of northern Malaysia. Presently, although the political motivation no longer exists, the construction of permanent settlements continues in response to socioeconomic issues. Administrative and commercial projects related to Orang Asli, such as the construction of schools, organization of health services, and the development of plantations are being completed on permanent settlements.

The de facto population consists of 48 men and 65 women (a total of 113) living in 18 households. Almost all villagers are Semaq Beri with the exception of two households whose legal heads-of-household are Bateq. These Bateq men came from the Bateq community nearby, which other ethnographer described (Lye 2005: p. 182), and married into their wives' families. 


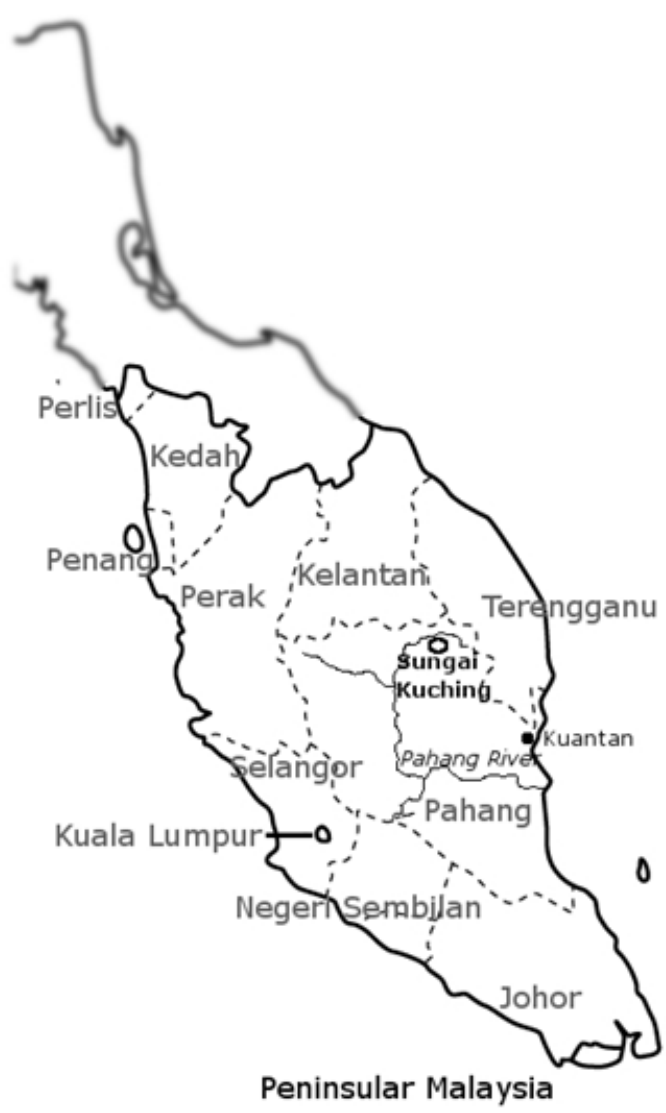

Figure 1. Location of the subject village

In addition, members of two different households moved from the village Sungai Berua, Terengganu. The Sungai Berua people are mostly same Semaq Beri. Some of them have the same lineage as the Sungai Kuching people. Moving between villages is considered common behavior. For example, unmarried people spend long periods of time at home or in other villages. Despite these marginal cases, the Sungai Kuching people constitute a community, following a patrilineal system and being characterized by the cooperation among its members.

Households are primarily nuclear comprising a husband, wife, and their children. They inherited this household organization from ancestors who lived in camps in forests (Dentan et al. 1997: pp. 24-26). At present, families live in concrete houses in permanent settlements constructed by JHEOA as a part of their development projects. Infants and children are expected to spend most of their time with household members in concrete houses. Some children attended preschool and elementary school in a nearby village. However, owing to various problems (discrimination, financial problems, fear, etc.), almost all children dropped out of school.

At the time of the research, rattan foraging was their primary source of income. Based on findings from preceeding studies conducted on surrounding populations (Kuchikura 1988), the people hunted or gathered food for daily consumption. Thus, they received the name "hunter-gatherer." Although hunting and gathering activities continue, subsistence transition along with modernization and/or globalization has changed the function of these activities from food production to income earning. Such changes will affect gender roles in subsistence activities and in daily life.

Rattan foraging usually entails several days of travel by motorboat through a system of rivers. These trips are usually organized by adult males. In addition to rattan gathering, the men collect aromatic plants (Aqularia spp.), soft-shelled turtles (Amyda cartilaginea), and fruits and seeds to sell for cash. On foraging trips, it is customary to eat some of these gathered fruits and seeds, while purchased foods such as rice or canned foods are consumed regularly when the men are in the village. Some villagers work for wages on the rubber plantation developed by JHEOA in the reserve area surrounding the village.

\section{Quantitative Methods}

This study relied primarily on the time allocation survey method to understand the differences in time spent by males and females on daily activities and childcare. Initially, we adopted the "observation at fixed spot method" 
(Suda 1994) to investigate the more general gender roles in society. In this method, an observer chooses a location where he or she can observe subjects as they move about and participate in daily activities. The author chose the jetty as his observation point because almost all the villagers walked through the jetty regularly. Additionally, all the household's houses in the village were located within viewing distance from the jetty. The subjects included 18 adult males and females and all of them were members of one of the nine chosen households. Observations were conducted during a one-week period from September 1-7. Each day, during a twelve-hour time span (07:00-19:00), all the subject activities were recorded. If a subject was absent from the village on particular time, the author interviewed the subject after his or her return. In order to complement the interview, notes were made of all items the subject carried while leaving from and returning to the village.

In order to quantify childcare activities, this study adopted a method similar to that used in a preceeding study conducted in Sungai Berua village (Kuchikura 2010). Five children (the youngest child in five different households) aged six months to two years were directly observed on an hourly basis for twelve hours (07:00-19:00). The observations were conducted from September 8-14. The questions guiding the observation were the following: (1) Who was most engaged in proximity maintenance for the child subject (to be judged by identifying the person who most often accompanied and closely cared for the child), and (2) Did the person with proximity maintenance hold or carry the child?

Prior studies that quantified hunter-gatherer childcare activities (Hewlett 1988, Peacock 1988, Tronick et al. 1992, Malrowe 2005, Hawkes et al. 1987) focused primarily on holding behavior, including nursing. Although this paper also studies holding behavior, it expands its focus to include the biological and sociocultural aspects of childcare. Thus, children of weaning age were selected as subjects (Note 4). Although earlier studies adopted various methods to quantify proximity maintenance for children, the method adopted by Kuchikura and Hewlett focused on the individual who was the closest to the child subject. The present study applies the same method. Although it is possible to quantify the proximity maintenance engaged in by more than one individual, it is important to examine not only the interactions between an individual and the child but also interactions among individuals (e.g., Tronick and Winn 1992). Because the aim of this study was to compare the difference between male and female individuals, we judged proximity maintenance based on who the individual closest to the child subject was.

\section{Results}

The results of the time allocation survey reveal significant differences in the time spent by male and female subjects on daily activities (Table 1). Among the activities in the table, "Foraging Fruits," "Foraging Rattan," and "Processing Rattan" are cash earning activities. Individuals engaged in "Foraging Fruits" collect fruits such as Nephelium lappaceum to sell in the market. Those engaged in "Processing Rattan" cut and strip raw rattan to sell to brokers. A "Foraging Trip" is a remarkable activity; usually, a male individual organizes a party of around 10 people who collect rattan or other products while camping in the forest for several days. A "Foraging Trip" may have had its origins in the Semaq Beri's former way of life. However, current practice might be different because this trip is restricted to men. Additionally, a permanent residence is required to store and process materials recovered during the trip. Like another survey, this time allocation survey also focuses on the activities of "Caring for Children" and "Nursing." However, this time allocation survey does not restrict the study of "caring" to proximity maintenance practiced by one person. In addition, "Nursing" included both breastfeeding and bottle-feeding with formula.

The results show that males spent significantly more time on the foraging trip. Although not statistically significant, males spent more on other cash earning activities also (foraging rattan and fruits). Females spent significantly more time on housekeeping and cooking. This study reveals that the present day Semaq Beri have biased gender roles in subsistence activities. These results also verify the earlier research performed by Kuchikura who found that males primarily engaged in cash earning activities, while females engaged in housekeeping activities. 
Table 1. Differences in time spent on daily activities (average hours)

\begin{tabular}{|c|c|c|c|c|c|c|}
\hline & Hunting & Fishing & $\begin{array}{l}\text { Foraging } \\
\text { Fruits }\end{array}$ & $\begin{array}{l}\text { Foraging } \\
\text { Rattan }\end{array}$ & $\begin{array}{c}\text { Foraging } \\
\text { Other Items }\end{array}$ & $\begin{array}{c}\text { Processing } \\
\text { Rattan }\end{array}$ \\
\hline Male & 0.73 & 0.52 & 0.94 & 0.57 & 0.17 & 0.13 \\
\hline Female & 0.00 & 1.98 & 0.19 & 0.02 & 0.14 & 0.38 \\
\hline \multirow[t]{2}{*}{ t-test* } & $\mathrm{P}<0.05$ & $\mathrm{P}<0.05$ & & & & \\
\hline & $\begin{array}{l}\text { Processing } \\
\text { Other Items }\end{array}$ & $\begin{array}{l}\text { Foraging } \\
\text { Trip }\end{array}$ & $\begin{array}{c}\text { Other } \\
\text { Subsistence } \\
\text { Activities }\end{array}$ & $\begin{array}{c}\text { Housekeeping } \\
\text { Activities }\end{array}$ & Cooking & $\begin{array}{l}\text { Caring } \\
\text { Children }\end{array}$ \\
\hline Male & 0.06 & 2.57 & 0.10 & 0.08 & 0.11 & 0.25 \\
\hline \multirow{3}{*}{$\begin{array}{c}\text { Female } \\
\text { t-test }\end{array}$} & 0.06 & 0.00 & 0.11 & 1.06 & 1.33 & 0.48 \\
\hline & & $\mathrm{P}<0.05$ & & $\mathrm{P}<0.05$ & $\mathrm{P}<0.05$ & \\
\hline & Nursing & $\begin{array}{c}\text { Visiting } \\
\text { Other Village }\end{array}$ & Eating & Resting & $\begin{array}{l}\text { Talking or } \\
\text { Playing }\end{array}$ & $\begin{array}{c}\text { Other } \\
\text { Activities }\end{array}$ \\
\hline Male & 0.13 & 0.24 & 1.11 & 1.63 & 1.65 & 1.00 \\
\hline $\begin{array}{c}\text { Female } \\
\text { t-test }\end{array}$ & 0.35 & 0.59 & 1.06 & 1.35 & 2.14 & 0.75 \\
\hline
\end{tabular}

*t value was calculated by two tailed test.

Preceeding studies have described the Orang Asli society as gender egalitarian (e.g., Nicholas, C. et al. 2002: pp79-85). However, although these descriptions emphasized that power differences did not exist during social interactions, they did not deny the existence of biased gender roles in subsistence activities. The results of the present study contrast male hunting practices with female fishing practices; both practices were unrelated to cash earning. However, the gender difference of cash earning activities as opposed to housekeeping activities could cause power differences in society. A preceeding study described a similar power difference observed in a Semai community (Nicholas, C. et al. 2002: pp112-113).

Although females spent more time engaged in childcare and nursing activities, there were no significant differences. In the present survey, all types of childcare activities, such as diaper changing or cradling, were grouped under the category "Caring for Children." Therefore, the total amount of time recorded for this category was underestimated. Usually, childcare occurred simultaneously with other activities, such as eating and talking. Another survey observed this synchronicity by focusing on the proximity maintenance practiced by one person. The lack of significant differences in "Nursing" activities suggests male involvement in childcare and that bottle-feeding with formula is popular in Semaq Beri.

Figure 2 shows the amount of time each person engaged in proximity maintenance with each of the five child subjects. We classified these individuals into six categories (Note 5). During the survey period, the child subjects' fathers travelled together on a three-day rattan foraging trip (Note 6). Our analysis compared two periods: (1) a seven-day period that included all data, and (2) a four-day period that showed the consequences of the fathers' absence. Asterisks mark two data sets of males and females (father and mother, other males and other females) that showed significant differences on the two-tailed t-test.

The results of the seven-day period showed no significant differences even though mothers spent more time with child subjects than any other individual including fathers did. Other males and females, including siblings and relatives, engaged in proximity maintenance far less than parents did. Other females engaged in proximity maintenance for longer periods than other males did. The results from the four-day period show a significant difference: mothers spent more time with their children than fathers did. A comparison of the seven-day and four-day results, reveal that child subjects spent longer amounts of time alone during the four-day period. However, because the results of the time spent on the "Other Situation" during the seven-day period was not at an ignorable level, we judged the cause to be ambiguous. 


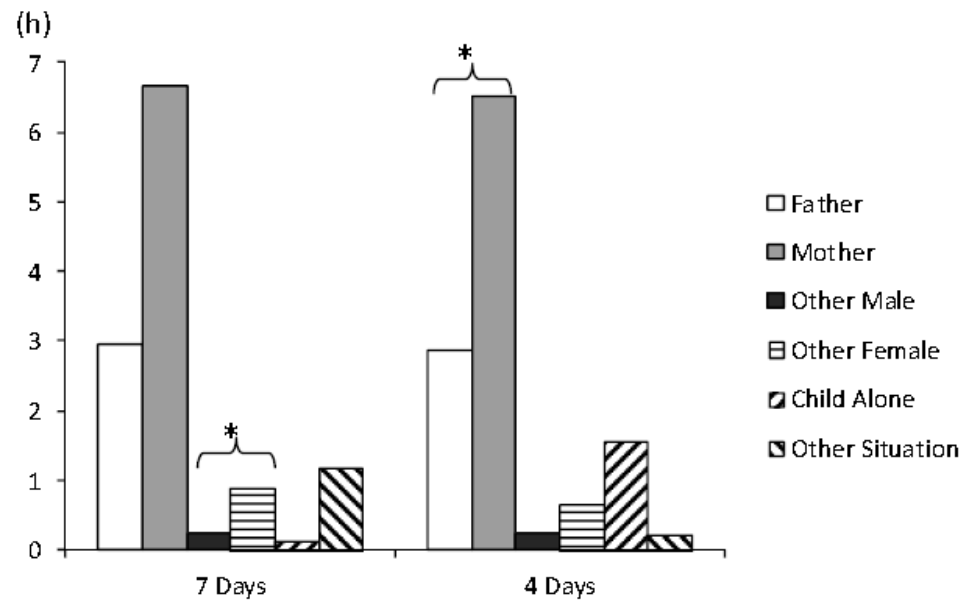

* Significant difference calculated by two-tailed t-test; $p<0.05$.

Figure 2. Time spent for proximity maintenance (average hours)

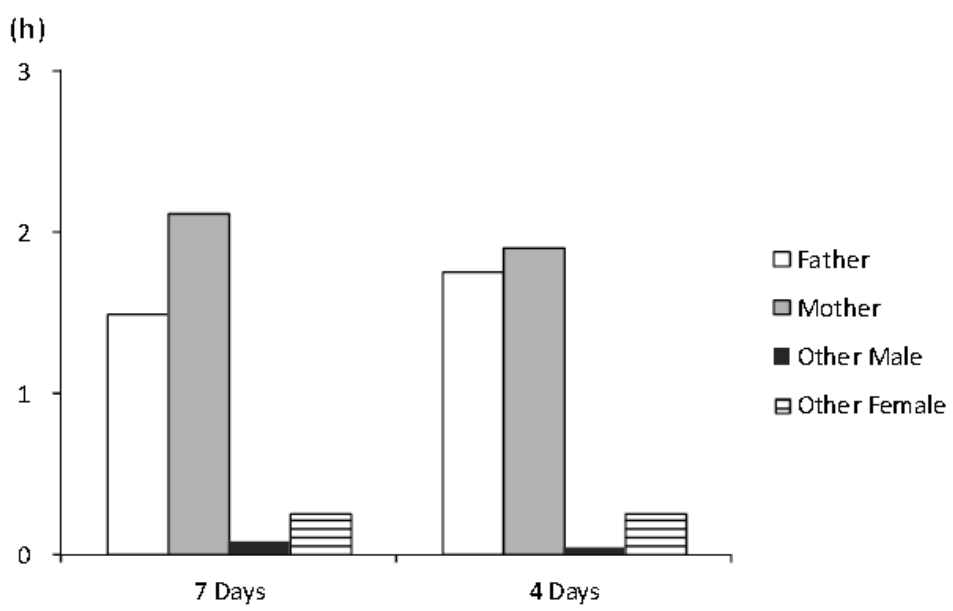

Figure 3. Time spent for holding and carrying children (average hours)

Figure 3 shows the four categories of individuals involved with the child subjects and the time each individual spent on holding and carrying activities. There were no significant differences between the "Father" and "Mother," and the "Other Male" and "Other Female" categories in the results of the four-day and seven-day periods. During the seven-day period, mothers held or carried children slightly longer than fathers did. During the four-day period, it was notable that fathers and mothers spent equal amounts of time with child subjects.

\section{Childcare in Semaq Beri}

Findings from the Sungai Kuching survey showed that fathers and mothers held and carried children for equal lengths of time. This may have been due, in part, to male participation in nursing activities. However, time spent by mothers in proximity maintenance was double the time spent by fathers. Table 2 shows the time spent in proximity maintenance by parents in six countries. These figures were collected by questionnaire survey. A comparison of the results of this study and these figures reveal that the amount of time spent in proximity maintenance by Sungai Kuching parents was equal to that spent by parents in Japan or Korea, where low levels of male involvement in childcare have been reported.

Table 2. Amount of time spent together with child by gender of parents (average hours)*

\begin{tabular}{lllllll}
\hline & Japan & Korea & Thailand & USA & France & Sweden \\
\hline Fathers & 3.08 & 2.78 & 5.89 & 4.6 & 3.79 & 4.61 \\
Mothers & 7.57 & 7.13 & 7.09 & 7.1 & 5.71 & 5.81 \\
\hline
\end{tabular}

*Data were quoted and modified from International Comparative Research on "Home Education" 2005: Survey on Children and the Family Life; pp. 87 Table II -2-6 [National Women's Education Center of Japan 2005] 
These results suggest that male involvement in all types of childcare activities in Sungai Kuching is not particularly high. Similarly, participant observation by the author revealed that childcare was considered a maternal duty. However, the results show that holding and carrying behavior were demonstrated to a high degree. These results do not contradict findings from former studies. Regarding holding and carrying behavior, we refer to a previous study that highlights Orang Asli society's gender egalitarian aspects (e.g., Endicott 1992). Although this study lacked historical methods, when we discuss "Malayanization" or social changes, it is possible to conclude that gender roles relating to childcare have changed in recent decades (e.g., Nicholas, C. et al. 2002). However, we could not reach a solid conclusion on this matter because these issues need further longitudinal studies.

The main finding of this study is that the amount of time fathers spent holding and carrying children was considerably high. Studies conducted from an evolutionary point of view (e.g., Hewlett 1991) found that this result is common in hunter-gatherer societies. However, earlier studies suggested that male involvement in childcare could also be observed during other activities. The results of this study did not show such generality. The findings of Kuchikura's study of the same Semaq Beri community (Kuchikura 2010) correspond with the results of this study. Therefore, this correspondence suggests that biased and non-biased aspects of gender role coexist ambiguously.

Despite this ambiguity, we found that holding and carrying children were important aspects of the hunter-gatherer lifestyle because temporal movement was indispensable to the pursuit dispersed resources. Studies conducted from an evolutionary point of view found that adult males and females shared holding and carrying behavior for reasonable amounts of time. Additionally, during occasional periods of frequent movement, only adult males were assigned holding and carrying activities. Although the people of Sungai Kuching now live in a permanent settlement, such gender role "survivals" through hunting and gathering dispersed resources. Future topics of research should include the exploration of holding and carrying behavior in other hunter-gatherer populations.

The results of this study show that people other than parents tended to not participle in childcare. The author's study on childcare in a farming community in Papua New Guinea discussed the extensive female involvement, particularly that of sisters, in childcare (Odani 2010). In addition, Kuchikura noted that in Sungai Berua, those other than parents did not participate in childcare. Due to insufficient data, it is hard to state whether parental or sibling participation in childcare is more common in hunter-gatherer populations than in farmer populations. However, in the creation of a study framework in gender studies, it is critical to focus on asymmetrical subjects. For example, questions for future study could include "Will the contribution of sisters in childcare decrease a father's involvement?" This study, in particular, is exceptionally symmetric.

It is difficult to apply these findings to all Orang-Asli societies, because each has its own subsistence activities and social situations. However, the diversity of subsistence activities (ranging from hunting, gathering, fishing, and cultivating to urban laboring) will provide ample opportunities for future study. In addition, future research should conduct additional comparative surveys to explain subsistence features including childcare activities and reveal the effects of modernization or "Malayanization" on these social situations.

\section{References}

Andaya, B. W., \& Andaya, L. Y. (2001). A history of Malaysia (2nd ed.). Basingstoke: Palgrave.

Blurton Jones, N. G. (1993). The lives of hunter-gatherer children: Effects of parental behavior and parental reproductive strategy. In M. Perreira, \& L. Fairbanks (Eds.), Juvenile Primates (pp. 309-326). Oxford: Oxford University Press, and New York.

Dentan, R., Knox, K. E., Gomes, A. G., \& Hooker, M. B. (1997). Malaysia and the "Original People": A Case Study of the Impact of Development on Indigenous Peoples. (Part of the Cultural Survival Studies in Ethnicity and Change Series) Boston: Allyn and Bacon.

Endicott, K. (1992). Fathering in an Egalitarian Society. In Barry S. Hewlett (Ed.), Father-Child Relations: Cultural and Biosocial Contexts (pp. 281-295). Chicago: Aldine.

Endicott, K. M., \& Endicott, K. L. (2007). The Headman Was a Woman. Long Grove: Waveland Pr Inc.

Hawkes, K., Kaplan, H., Hill, K., \& Hurtado, A. M. (1987). Ache at the Settlement: Contrasts between Farming and Foraging. Human Ecology, 15(2), 133-161. http://dx.doi.org/10.1007/BF00888378

Hewlett, B. S. (1988). Sexual selection and paternal investment among Aka pygmies. In L. Betzig, P. Turke, \& M. Borgerhoff Mulder (Eds.), Human Reproductive Behavior: A Darwinian Perspective (pp. 263-276). 
Cambridge: Cambridge University Press.

Hewlett, B. S. (1991). Intimate Fathers: The Nature and Context of Aka Pygmy Paternal Infant Care. Ann Arbor: University of Michigan Press.

Jabatan Hal Ehwal Orang Asli. (2006). The Population of Orang Asli in Malaysia. Kuala Lumpur: Jabatan Hal Ehwal Orang Asli.

Katz, M. M., \& Konner, M. J. (1981). The role of the father: An anthropological perspective. In M. Lamb (Ed.), The role of the father in child development (pp. 155-185). New York: John Wiley and Sons.

Konner, M. J. (2005). Hunter-gatherer infancy and childhood: The! Kung and others. In B.S. Hewlett, \& M. Lamb (Eds.), Hunter-gatherer childhoods: Evolutionary, developmental and cultural perpectives (pp.19-64). New Brunswick: Transaction Publishers.

Kuchikura, Y. (1988). Efficiency and Focus of Blowpipe Hunting among Semaq Beri Hunter-Gatherers of Peninsular Malaysia. Human Ecology, 16(3), 271-305. http://dx.doi.org/10.1007/BF00888448

Kuchikura, Y. (2010). The Infant Care in a Semaq Beri Community of Peninsular Malaysia: An Examination Based on the Time Allocation Study. (In Japanese) Bulltin of the Faculty of Regional Studies, 26, 51-88.

Lye Tuck-Po. (2005). Changing pathways: forest degradation and the Batek of Pahang, Malaysia. Selangor: Strategic Information Research Development.

Marlowe, F. W. (2005). Who tends Hadza children? In B. S. Hewlett, \& M. Lamb (Eds.), Hunter-Gatherer Childhoods: Evolutionary, Developmental and Cultural Perspectives (pp. 177-190). New Brunswick: Transaction.

National Women's Education Center of Japan. (2007). International Comparative Research on "Home Education" 2005: Survey on Children and the Family Life. Tokyo: National Women's Education Center of Japan.

Nicholas, C., Chopil, T. Y., \& Sabak, T. (2002). Orang Asli Women and The Forest: The Impact Of Resource Depletion On Gender Relations Among The Semai. Kuala Lumpur: Center for Orang Asli Concerns.

Odani, S. (2010). Sister as a Habitus: Demographic Anthropological Ethnography of Gender-Biased Mortality in Childhood. (In Japanese) Tokyo: University of Tokyo Press.

Peacock, N. R. (1985). Time Allocation, Work and Fertility among Efe Pygmy Women of Northeast. Zaire. Ann Arbor: UMI Dissertation Information Service.

Suda, K. (1994). Methods and problems in time allocation studies. Anthropological Science, 102, 13-22.

Thurer, S. (1995). Myths of Motherhood: How Culture Reinvents the Good Mother. Penguin. http://dx.doi.org/10.1537/ase.102.13

Tronick, E. Z., \& Winn, S. A. (1992). The neurobehavioral organization of Efe (pygmy) infants. Journal of Developmental and Behavioral Pediatrics, 13(6), 421-424. http://dx.doi.org/10.1097/00004703-199212000-00006

Tronick, E. Z., Morelli, G. A., \& Winn, S. A. (1987). Multiple Caretaking of Efe (Pygmy) Infants. American Anthropologist, 89, 96-106. http://dx.doi.org/10.1525/aa.1987.89.1.02a00050

\section{Notes}

Note 1. Semaq Beri are part of the Senoi group (Semaq Beri, Temiar, Jah- het, Ma' Betise', and Chewong). Administratively, Orang Asli can be divided into three groups and eighteen subgroups. Senoi are the largest group; they comprise $56 \%$ of Orang Asli population. The second largest group (Proto-Malay) comprises $41 \%$ of the population. This group includes Temuan, Jakun, Semelai, Orang Seletar, Orang Kuala, and Orang Kanaq. The third largest group, Negrito, comprise $3 \%$ of the population. Negrito includes Kintak, Kensiu, Jahai, Mendrik, Batek, and Lanoh. According to the 2005 census, the total population of Orang Asli was 141,230 (JHEOA 2006).

Note 2. The Bumiputera categorization and other policies implemented by the Malaysian government, by which Muslim Malays and Orang Aslis are categorized under "Bumiputera," are representative (Andaya and Andaya 2001: pp. 3-4). Almost all Orang Aslis are minorities, and their sociocultural aspects of their lives conform to those of the Muslim Malay majority. 
Note 3. In 2011, JHEOA was reorganized into JAKOA (Jabatan Kemajuan Orang Asli; Department of Orang Asli Development). In 1954, JOA (Jabatan Orang Asli) was established. In 1963, JOA's name was changed to JHEOA.

Note 4. Kuchikura pointed out that the Semaq Beri parents in Sungai Berua began to wean children at six months of age with foods like sugared rice porridge. Usually, children were completely weaned by two years of age (Kuchikura 2010).

Note 5. Other situations included cases where the author did not identify an individual who was closest to the subject child and lost track of the child.

Note 6. The foraging trip was organized by adult males. Only fathers of child subjects participated. Although on the second day, fathers did not spend any time with children, on the first day and third days they spent time with child subjects both before and after the trip. 